\title{
Anti-mesothelin Antibody-drug Conjugate BMS-986148
}

National Cancer Institute

\section{Source}

National Cancer Institute. Anti-mesothelin Antibody-drug Conjugate BMS-986148. NCI

Thesaurus. Code C120303.

An antibody-drug conjug ate (ADC) composed of a monoclonal antibody directed against the cell surface glycoprotein mesothelin and conjug ated to an as of yet undisclosed cytotoxic drug, with potential antineoplastic activity. The monoclonal antibody moiety of anti-mesothelin ADC BMS-986148 targets and binds to the tumor associated antigen mesothelin. Upon internalization, the cytotoxic agent kills or prevents cellular proliferation of mesothelin-expressing tumor cells through an as of yet undescribed mechanism of action. Mesothelin is overexpressed by all mesotheliomas and a variety of other cancers, while it is minimally expressed in normal tissue. 